\title{
ПРИМЕНЕНИЕ МАТЕМАТИЧЕСКОЙ МОДЕЛИ ДЛЯ ПРОГНОЗИРОВАНИЯ ЭПИДЕМИОЛОГИЧЕСКОЙ СИТУАЦИИ ПО COVID-19 В РОСТОВСКОЙ ОБЛАСТИ.
}

\author{
А.В. Алешукина, В.В. Денисенко, Г.С. Алешукин, Е.В. Голошва \\ ФБУН «Ростовский научно-исследовательский институт микробиологии и \\ паразитологии» Роспотребнадзора
}

11 марта 2020 года ВОЗ объявила о пандемии новой короновирусной инфекции (COVID-19) [1]. В Российской Федерации первые заболевшие COVID-19 были зафиксированы в конце января 2020 года (приезжие граждане КНР). Массовое распространение инфекции в западных регионах РФ произошло в начале марта 2020 года. Инфекция была занесена гражданами РФ, возвращающимися из стран Европы, охваченных эпидемией COVID-19. В дальнейшем эпидемия COVID-19 в РФ приняла серьезные масштабы [2].

B Ростовской области первый случай выявления COVID-19 был зарегистрирован 25 марта 2020 года у женщины, прибывшей из стран дальнего зарубежья незадолго до проявления симптомов заболевания. С этого дня регистрировался единичный прирост случаев заболевания до 6 апреля 2020 года. Затем начали выявляться десятки случаев заболевания, а с 16 мая 2020 года - более 100 случаев ежедневно. На данный момент (20.07.2020) в Ростовской области зарегистрировано 11419 случаев новой короновирусной инфекции, коэффициент распространения инфекции составляет 1,02, показатель заболевших на 100 тысяч населения - 271,8, смертей - 183. Выздоровели в области за весь период эпидемии 8909 человек [3,4,5].

Пандемия опасна тем, что одновременное заболевание инфекцией множества людей может привести к перегруженности системы здравоохранения с повышенным количеством госпитализаций и летальных исходов. Системы здравоохранения могут оказаться не готовы к необычайно большому количеству тяжелобольных пациентов.

Наиболее важной ответной мерой по отношению к инфекции являются не лечебные мероприятия, а снижение скорости её распространения, чтобы растянуть её во времени и снизить, таким образом, нагрузку на системы здравоохранения. Для расчетов вариантов возможных мер по снижению нагрузки на медицинские учреждения, а также сроков снятия карантинных мер используется математическое моделирование [6]. Если учесть такие параметры эпидемического процесса, как скорость заражения, скорость выздоровления, частоту летальных исходов, можно, с достаточной долей вероятности, 
рассчитать, как после внедрения в популяцию людей или животных какого-либо патогена будут вести себя кривые, демонстрирующие с течением времени количество незараженных, больных и выздоровевших индивидуумов.

На данный момент существуют различные классы математических моделей, применяемых для прогнозирования течения эпидемий $[7,8,9]$. Класс моделей SRID (Susceptible - восприимчивый, Recovered - выздоровевший, Infectious - инфицированный, Deceased - умерший) предусматривает формирование устойчивого иммунитета к инфекции (повторное заражение невозможно). Класс моделей SIR (Susceptible восприимчивый, Infectious - инфицированый, Recovered - выздоровевший) - модель с формированием устойчивого иммунитета - является базовой моделью для описания распространения эпидемий. Класс моделей SIS (Susceptible - восприимчивый, Infected выздоровевший, Susceptible - восприимчивый) - модель без устойчивого иммунитета с возможным хроническим течением болезни. SIS-модели хорошо зарекомендовали себя при описании опасных вирусных заболеваний с хроническим течением, таких как вирус иммунодефицита человека (HIV), хронические гепатиты B (HBV) и C (HCV). Модели SIR применяются для описания эпидемических процессов, вызываемых вирусами с относительно легким течением: группы вирусов, вызывающих респираторные инфекции (ОРВИ) и некоторые штаммы вируса гриппа (influenza virus) [10].

Модель SIR, предложенная еще в 1920-х годах Керманом и МакКендриком, дает базовое качественное понимание динамики распространения инфекционных заболеваний, но для количественного моделирования этой динамики требуются различные уточнения, учитывающие особенности протекания конкретных болезней. Так, важной особенностью многих болезней является наличие инкубационного периода, в течение которого человек уже является носителем болезни, но не демонстрирует симптомов и не является заразным для окружающих. Эта особенность может быть учтена разделением группы зараженных (Infected) на две подгруппы - экспонированных (Exposed), т.е. зараженных в стадии инкубационного периода, и заразных (Infections). Таким образом, модель SIR преображается в модель SEIR [7,11]

Модель SEIR - самый распространенный инструмент для прогнозирования эпидемий и действенности мер по их подавлению. В 2020 году модель была доработана Ричардом Нейером и его сотрудниками в Базельском университете с учетом особенностей эпидемии нового коронавируса. Модель реализована в виде компьютерной программы для моделирования эпидемии COVID-19, доступной в интернете [12]. Расчеты по этому 
варианту SEIR, в частности, использовались при принятии решения о введении ограничительных мер в штате Иллинойс и в его крупнейшем городе Чикаго.

Основное свойство модели SEIR - наличие так называемого эпидемического перехода: модель ведет себя радикально по-разному в зависимости от показателя $\mathrm{R}_{0}$ (базовое репродуктивное число) - среднего числа людей, которых один зараженный успевает заразить за время, пока сам не выздоровеет. При $\mathrm{R}_{0}$ меньше единицы эпидемия затухает, при показателе больше единицы заражается значительная часть населения. Значение $\mathrm{R}_{0}$ зависит от особенностей вируса, доли населения, получившей иммунитет (в результате вакцинации или пережитого заболевания), а также мер по подавлению эпидемии (различные формы карантина) [13].

Моделирование показывает, с какой скоростью будет распространяться эпидемия, сколько будет заразившихся, жертв, а также больных в критическом состоянии. Последний показатель сравнивается с мощностями медицинской системы для определения - способна ли она справиться с наплывом пациентов, нуждающихся в специализированной помощи: в случае с коронавирусной инфекцией это реанимация, искусственная вентиляция легких и т. д.

Доработанная для COVID-19 модель учитывает все основные параметры эпидемии:

- д долю тяжелых больных и уровень летальности в зависимости от возраста больных. Поскольку тяжелые случаи чаще встречаются у людей старшего возраста, учитывается возрастная структура населения;

- длительность инкубационного периода и заразной фазы болезни;

распространенности бессимптомного протекания болезни и недостаточного тестирования;

• возможные сезонные изменения заразности вируса;

- $\quad$ возможные меры сдерживания и подавления эпидемии и их влияние на $\mathrm{R}_{0}$;

Целью нашей работы явилось проведение математического моделирования развития эпидемии COVID-19 в Ростовской области, основанного на данных за два различных периода. Первый прогноз составлен, исходя из данных в условиях реализации в области жестких ограничительных мер и режима самоизоляции, второй - в условиях постепенного снятия ограничительных мер. 
Для моделирования распространения COVID-19 в Ростовской области нами использовалась интерактивная SEIR-модель [12] реализованная в виде web-приложения [14].

При проведении расчетов в первоначальном варианте нами использовались следующие начальные значения:

Численность популяции — 4197821 чел. (население Ростовской области на 01.01.2020 г.).

Возрастная структура популяции

\begin{tabular}{|l|l|l|}
\hline $\begin{array}{l}\text { Возрастная } \\
\text { группа }\end{array}$ & Численность, чел. & Доля, \% \\
\hline $0-9$ & 535681 & $12,76 \%$ \\
\hline $10-19$ & 438842 & $10,45 \%$ \\
\hline $20-29$ & 448960 & $10,70 \%$ \\
\hline $30-39$ & 703841 & $16,77 \%$ \\
\hline $40-49$ & 586098 & $13,96 \%$ \\
\hline $50-59$ & 543593 & $12,95 \%$ \\
\hline $60-69$ & 532194 & $12,68 \%$ \\
\hline $70-79$ & 245934 & $5,86 \%$ \\
\hline $80+$ & 162678 & $3,88 \%$ \\
\hline Всего & 4197821 & $100 \%$ \\
\hline
\end{tabular}

- $\quad$ Начальное число зараженных 5 (на начало моделирования).

- Количество коек для COVID-19 пациентов - 2664, в отделениях интенсивной терапии - 969.

- Дата начала моделирования - 25.03.2020 - дата первого выявленного случая COVID-19 в Ростовской области.

- Дата окончания моделирования - 01.09.2020.

- Среднегодовой коэффициент воспроизводства в отсутствие сдерживающих мер $\mathrm{R}_{0}=4,2$.

- $\quad$ Длительность латентного (незаразного) периода - 5,2 дня.

- Продолжительность периода заразности - 2,8 дня. 
- Сезонность вируса - 20 \% увеличения заразности зимой и 20 \% снижения заразности летом, пик заразности - январь.

- Эффективность мер противодействия - (режим самоизоляции, увеличение количества тестов) оценена в 80 \%.

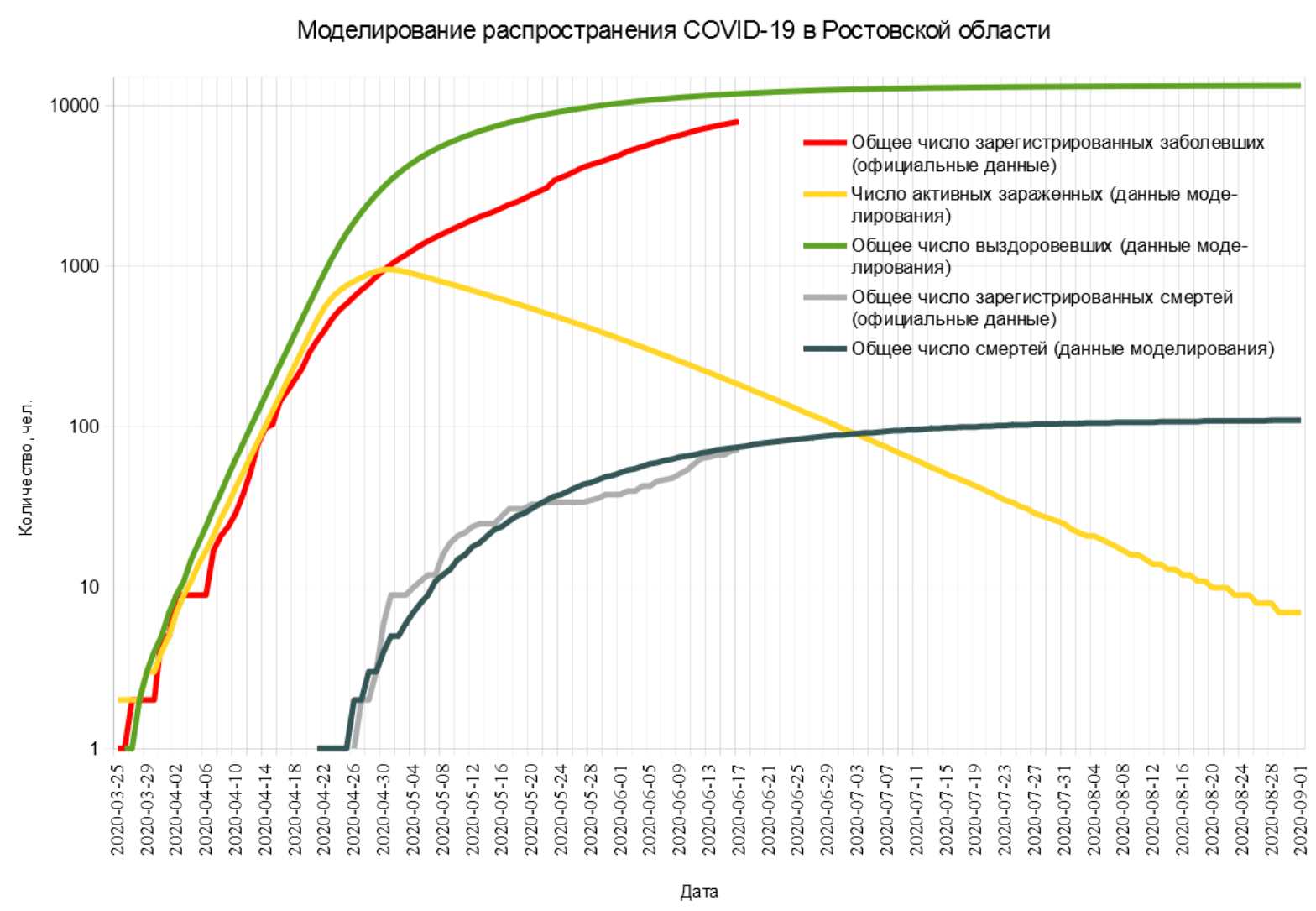

Таблица 1: Прогноз эпидемиологической ситуации по COVID-19 в Ростовской области на 01.09.2020 в случае сохранения действующих ограничительных мер (данные моделирования на начало июня)

\begin{tabular}{|c|c|}
\hline Число активных зараженных, чел. & 7 \\
\hline Общее число выздоровевших, чел. & 13307 \\
\hline Число госпитализированных, чел. & 3 \\
\hline $\begin{array}{c}\text { Число госпитализированных } \\
\text { отделения интенсивной терапии, чел. }\end{array}$ & 1 \\
\hline Общее число смертей, чел. & 110 \\
\hline
\end{tabular}


Построенные по этим значениям с использованием SEIR-модели графики показали, что в целом предсказываемые значения развития событий тождественны тем, что были выявлены в ходе развития пандемии на том этапе. Встречаемые отклонения легко могли быть обусловлены теми или иными непрогнозируемыми событиями (вспышки в закрытых учреждениях, нарушения режима самоизоляции, изменения погодных условий).

Данный прогноз составлялся исходя из данных на начало июня, в условиях жестких мер. Кроме того, учитывался момент, что ограничительные меры по режиму самоизоляции, если и не будут ослабляться, то хотя бы останутся на прежнем уровне. Но развитие ситуации показало, что в сложившейся ситуации наблюдается тенденция по ухудшению прогноза. По большому счету, все действия по снижению масштаба эпидемии направлены на снижение коэффициента $\mathrm{R}_{0}$ (среднее число людей, которых один зараженный успевает заразить за время, пока сам не выздоровеет). Снижение $\mathrm{R}_{0}$ приводит качественно к двум результатам: (а) снижению общего числа заразившихся за время эпидемии и (б) увеличению ее длительности и, соответственно, снижению числа болеющих в каждый заданный момент времени, что снижает единовременную нагрузку на систему здравоохранения. При этом, важно иметь в виду, что при небольшом уменьшении $\mathrm{R}_{0}$ главную роль играет эффект удлинения эпидемии, в то время как снижение $\mathrm{R}_{0}$ ниже единицы полностью подавляет эпидемию, и, соответственно, общее число переболевших становится незначительным по сравнению с размерами популяции. В случае подавления эпидемии не вырабатывается групповой иммунитет, и при новом повышении $\mathrm{R}_{0}$ после снятия карантинных ограничений возникает риск второй волны эпидемии [15].

Поскольку эпидемия COVID-19 особенно опасна для пожилых людей, необходимо рассматривать различные тактики сдерживания, преимущественно направленные, прежде всего, на снижение заражения пожилых людей.

Основными методами снижения $\mathrm{R}_{0}$ являются (а) изоляция заболевших и (б) общее снижение числа социальных контактов в популяции. В случае COVID-19 изоляция заболевших людей, по-видимому, недостаточно эффективный способ борьбы с распространением эпидемии. Это связано с большим количеством легких и бессимптомных, но, тем не менее, заразных случаев, а также с тем, что заражение, как правило, происходит на ранней стадии, когда больные еще не диагностированы. В этом, кстати, радикальное отличие COVID-19 от SARS (атипичная пневмония) — другой очень заразной болезни, вызываемой коронавирусом. SARS в среднем протекает гораздо тяжелее, чем COVID-19, больные становятся заразными тогда, когда уже чувствуют себя плохо. Это свойство позволило остановить эпидемию SARS путем выявления и изоляции 
заразных больных. Поэтому на данном этапе основные доступные большинству стран, включая и Россию, методы сдерживания - это методы, более или менее принудительно снижающие общее число социальных контактов в популяции в целом. [16]

Снижение коэффициента $\mathrm{R}_{0}$ меньше единицы позволило правительству Ростовской области перейти к мерам по ослаблению карантинных мер, что способствовало оживлению экономики области, но, в свою очередь, привело к изменению прогноза развития пандемии COVID-19 в Ростовской области. С целью актуализации моделирования нам пришлось скорректировать вводные данные. Корректировке подверглись следующие значения:

- Начальное число зараженных 200 (на начало моделирования).

- Количество коек для COVID-19 пациентов - 2664, в отделениях интенсивной терапии - 969.

- Дата начала моделирования - 25.03.2020 — дата первого выявленного случая COVID-19 в Ростовской области.

- Дата окончания моделирования - 01.09.2020.

- Среднегодовой коэффициент воспроизводства в отсутствие сдерживающих мер $\mathrm{R}_{0}=4,2$.

- Длительность латентного (незаразного) периода - 3 дня.

- Продолжительность периода заразности - 3 дня.

- Сезонность вируса - отсутствует.

- Эффективность мер противодействия - (режим самоизоляции, увеличение количества тестов) оценивалась в 60-75\%. 


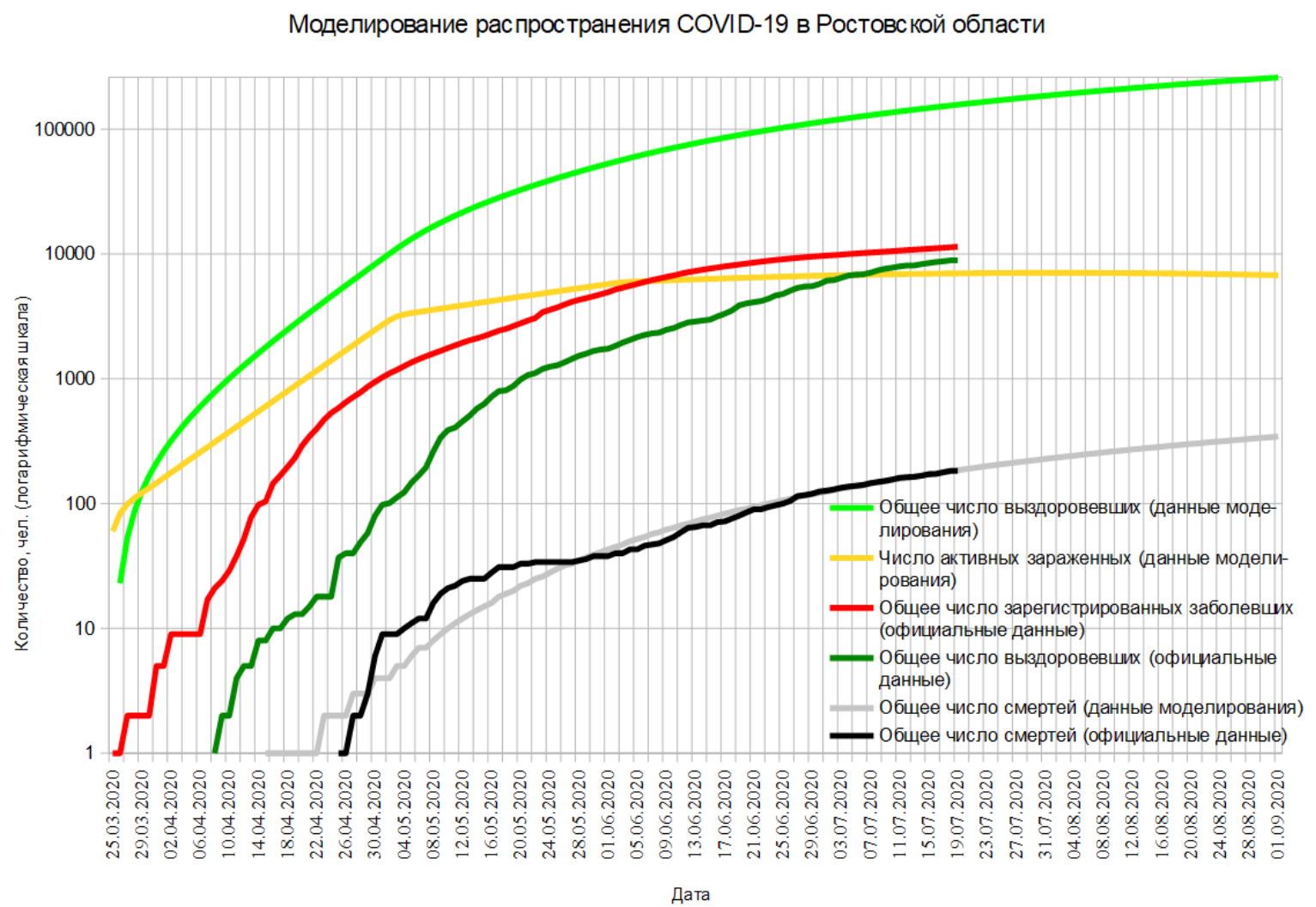

Таблица 2: Прогноз эпидемиологической ситуации по COVID-19 в Ростовской области на 01.09.2020 в случае сохранения действующих ограничительных мер (данные моделирования на 20.07.2020).

\begin{tabular}{|l|l|}
\hline Число активных зараженных, чел. & 6751 \\
\hline Общее число выздоровевших, чел. & 259161 \\
\hline Число госпитализированных, чел. & 801 \\
\hline $\begin{array}{l}\text { Число госпитализированных в отделения } \\
\text { интенсивной терапии, чел. }\end{array}$ & 46 \\
\hline Общее число смертей, чел. & 345 \\
\hline
\end{tabular}

Заключение. В результате проведенного исследования с учетом данных на 20.07.2020 года приходится констатировать тот факт, что общее количество жителей Ростовской области, инфицированных новым короновирусом, значительно превосходит официальную статистику. Имеется значительное количество неучтенных случаев легкого или бессимптомного течения заболевания, оканчивающегося выздоровлением и формированием иммунитета $\mathrm{K}$ данной инфекции. Применение математического моделирования развития эпидемии COVID-19 в Ростовской области с учетом реалий 
сегодняшнего дня дает основание предполагать, что частичное снятие ограничительных мероприятий способно усугубить ситуацию по COVID-19 в Ростовской области. Так, значительно увеличивается число прогнозируемых активных зараженных (6751), госпитализированных людей (801), общее число смертей может достигнуть 345 случаев на 01.09.2020 г. Общее число прогнозируемых выздоровевших, достигающее 259161 человек, является свидетельством того, что в нашем регионе имеется значительное количество неучтенных случаев заражения COVID-19, протекающих в легкой или бессимптомной форме. Положительным моментом в этой ситуации является формирование у выздоровевших людей иммунитета к данной инфекции (приблизительно 10 \% населения Ростовской области). Для улучшения прогнозируемой ситуации необходимо продолжать осуществление комплекса мероприятий, направленных на реализацию в области ограничительных мер (масочного режима, социального дистанцирования граждан, проведения масштабных мероприятий по дезинфекции и пр.). Для определения более точного числа переболевших новой короновирусной инфекцией граждан необходимо существенно расширить масштабы проводимого в области серологического тестирования на антитела (увеличить популяционную выборку).

\section{Литература}

1.Сайт BBC News.Русская служба [Электронный ресурс]:

URL:https://www.bbc.com/russian/features-52762747

2.Официальная информация о коронавирусе в России [Электронный ресурс]:

URL:https://стопкоронавирус.рф

3.Сайт регионального штаба Ростовской области [Электронный ресурс]:

URL:https://www.donland.ru/activity/2648/

4.Сайт Роспотребнадзора Ростовской области [Электронный ресурс]:

URL:http://61.rospotrebnadzor.ru

5.Сайт Минздрава Ростовской области [Электронный ресурс]:

URL:http://minzdrav.donland.ru

6. Кольцова Элеонора Моисеевна, Куркина Елена Сергеевна, Васецкий Алексей Михайлович. Математическое моделирование распространения эпидемии коронавируса COVID-19 в Москве. [Электронный ресурс].

URL:https://cyberleninka.ru/article/n/matematicheskoe-modelirovanie-rasprostraneniyaepidemii-koronavirusa-covid-19-v-moskve 
7. Kermack, W. O., \& McKendrick, A. G. (1927). A contribution to the mathematical theory of epidemics. Proceedings of the royal society of london. Series A, Containing papers of a mathematical and physical character, 115(772), 700-721.

8. Bailey, N. T. (1975). The mathematical theory of infectious diseases and its applications. Charles Griffin \& Company Ltd, 5a Crendon Street, High Wycombe, Bucks HP13 6LE.

9. Anderson, R. M., Anderson, B., \& May, R. M. (1992). Infectious diseases of humans: dynamics and control. Oxford university press Hethcote, H. W. (2000). The mathematics of infectious diseases. SIAM review, 42(4), 599- 653.

10. Букин Ю.С.. Джиоев Ю.П., Бондарюк А.Н., Ткачев С.Е., Злобин В.И. Применение универсальной математической модели эпидемического процесса «SRID» для прогноза развития эпидемии COVID-19 в городе Москва. [Электронный ресурс]. URL:https://www researchgate.net/publication/341411459.

11. Тамм М.В. Короновирусная инфекция в Москве: прогнозы и сценарии. Фармакоэкономика. Современная Фармакоэкономика и Фармакоэпидемиология. 2020. Том 13, № 1: 43-51.

12. Nicholas B Noll, Ivan Aksamentov, Valentin Druelle, Abrie Badenhorst, Bruno Ronzani, Gavin Jefferies, Jan Albert, Richard Neher. COVID-19 Scenarios: an interactive tool to explore the spread and associated morbidity and mortality of SARS-CoV-2. [Электронный ресурс]:

URL:https://doi.org/10.1101/2020.05.05.20091363

13. Моделирование эпидемий: дополнения к модели SIR. [Электронный ресурс].

URL: https://polit.ru/article/2020/05/27/sir/

14.COVID-19 Scenarios.[Электронный ресурс].

URL:https://covid19-scenarios.org/. Дата обращения 18.06.2020

15. « «Медуза». В Москве ввели жесткие карантинные меры. Похоже, это правильно: математическая модель показывает, что иначе могли бы погибнуть больше 100 тысяч человек» [Электронный ресурс].

URL: $\quad$ https://meduza.io/feature/2020/03/30/v-moskve-vveli-zhestkie-karantinnye-merypohozhe-eto-pravilno-matematicheskaya-model-pokazyvaet-chto-inache-mogli-by-pogibnutbolshe-100-tysyach-chelovek

16. «Медуза» спрогнозировала развитие эпидемии коронавируса в России Карантин можно будет снять в июне - но только если сейчас его ужесточить. [Электронный ресурс]. 
URL: $\quad$ https://meduza.io/feature/2020/04/17/meduza-sprognozirovala-razvitie-epidemiikoronavirusa-v-rossii-karantin-mozhno-budet-snyat-v-iyune-no-tolko-esli-seychas-egouzhestochit 